\title{
Perbandingan Antara Alur Kerja BIM Dengan CAD Pada Proses Renovasi Rumah Tinggal
}

\author{
Ardhiana Muhsin ${ }^{1}$, R. Yasyfa S Prawiradinata ${ }^{1}$, Yasmin Nur Razaq ${ }^{1}$, Novianti ${ }^{1}$ \\ ${ }^{1}$ Program Studi Arsitektur, Fakultas Arsitektur dan Desain, Itenas, Bandung \\ Email: dade@itenas.ac.id
}

\begin{abstract}
ABSTRAK
Building Information Modelling atau BIM menjadi topik pembicaraan bagi pelaku industri konstruksi yang diyakini dapat menambah efisisensi waktu pengerjaan proyek serta menghemat biaya proyek. Keberadaan konsep BIM ini juga semakin kuat dengan adanya peraturan dari Kementerian PUPR Nomor 22/PRT/M/2018 yang mensyaratkan penggunaan BIM dalam tender perencanaan diatas $2000 \mathrm{~m} 2$. Sejumlah pertanyaan muncul atas keraguan terhadap konsep BIM yang ditawarkan misalnya sejauh mana peningkatan efisiensi waktu pada proses perancangan dan juga tahap konstruksi. Konsep BIM yang juga mencakup tahapan renovasi sebagai bagian dari kegiatan pengelolaan bangunan turut menjadi pembahasan yang sering dibandingkan dengan alur kerja CAD tanpa menggunakan BIM. Selama ini dalam kegiatan renovasi, arsitek terkadang tidak memiliki data yang lengkap tentang bangunan yang akan dikerjakannya. Informasi yang hilang ini tidak jarang menuntun arsitek dan pemilik pada keputusan yang salah seperti mengganti ulang bahan penutup lantai karena kesulitan mendapatkan bahan yang sama atau bahkan lebih fatal lagi menyebabkan runtuhnya sebagian bangunan karena kesalahan dalam pembongkaran. Atas dasar hal tersebut, penelitian ini disusun dan menitikberatkan pada alur kerja tahapan renovasi dengan komparasi penggambaran digital dengan CAD yang tanpa BIM maupun menggunakan konsep BIM. Hal ini dimaksudkan untuk mendapatkan jawaban apakah konsep BIM dapat dipahami dan terlihat manfaatnya secara nyata
\end{abstract}

Kata kunci: Alur Kerja, Building Information Modelling, CAD, Penggambaran Digital, Renovasi

\begin{abstract}
Building Information Modelling or BIM become a major topic in construction industry which are believed to be able to increase the efficiency of project work time and will certainly save project costs. The existence of BIM concept is also enhancing after supported by the Ministry of PUPR in regulation no. 22/PRT/M/2018 by requiring the use of BIM in project qualification above $2000 \mathrm{~m} 2$. Numbers of questions then arise over doubts about the concept of BIM offered for example the extent of increased time efficiency in the design process and also the construction stage. The concept of BIM, which also includes renovation stages as part of building management activities, has also been discussed, which is often compared to workflows without using BIM. During this time in renovation activities, architects sometimes do not have complete data about the building that will be done. This missing information often leads architects and owners to wrong decisions such as replacing floor covering materials because of difficulty in obtaining the same material or even more fatally causing the partial collapse of the building due to errors in demolition. Based on this, this research was compiled and focused more on the workflow in the renovation stage with the comparison of commonly used methods and using the concept of BIM. This is intended to get answers on whether the concept of BIM can be understood and seen the benefits in real terms.
\end{abstract}

Keywords: Building Information Modelling, CAD, Digital Drawing, Renovation, Workflow 


\section{PENDAHULUAN}

Sektor industri konstruksi, sebagai bentuk nyata dari pembangunan, selalu dituntut untuk tanggap terhadap segala macam bentuk perkembangan teknologi yang ada. Penggambaran pada suatu proyek bangunan dalam bentuk digital dimulai dengan gambar dua dimensi, kemudian berkembang menjadi gambar tiga dimensi, saat ini penggambaran dimulai dengan memodelkan bangunannya terlebih dahulu disertai berbagai informasinya untuk kemudian dapat dikeluarkan datanya berupa gambar dua dimensi maupun tabel-tabel data. Proses ini yang kemudian dikenal dengan nama Building Information Modeling atau BIM. Building Information Modeling merupakan pendekatan baru dalam dunia konstruksi dengan tujuan untuk memperbaiki alur kerja dalam suatu proses pekerjaan agar tercipta efisiensi kerja serta adanya perluasan sistem kerja yang dapat menampung beberapa format digital yang berbeda. Pemerintah pun akhirnya melakukan penyesuaian dengan menerapkan BIM sebagai salah satu persyaratan dalam pekerjaan perencanaan bangunan gedung. Masuknya konsep alur kerja baru dalam suatu teknologi tidak diterima begitu saja bagi seluruh pelaku industri konstruksi. Pengenalan penggambaran arsitektur dalam bentuk digital dengan bantuan program Computer Aided Design atau CAD awalnya pun mengalami hambatan. Banyak pihak yang masih meragukan kemampuan konsep BIM apakah sesuai dengan gambaran yang diberikan disamping masalah investasi dalam perangkat keras, perangkat lunak dan sumber daya manusia yang harus disiapkan dan tentunya tidak memakan biaya yang sedikit [1]. Hal ini pula yang menjadikan perkembangan BIM di Indonesia menjadi kurang signifikan [2].

Kegiatan renovasi dalam bidang arsitektur merupakan tahapan kerja yang cukup menantang. Berbeda dengan pembangunan yang dimulai dari nol pada sebidang tanah kosong, kegiatan renovasi menuntut arsitek untuk mencermati terlebih dahulu kondisi eksisting bangunan yang ada untuk kemudian berkreasi dalam keterbatasan guna memenuhi kebutuhan yang diinginkan oleh pemberi tugas. Minimnya kelengkapan dokumentasi yang dimiliki oleh pemilik bangunan menambah rumit persoalan dan terkadang solusi pemecahan masalahnya sangat bergantung pada pengalaman arsitek atau pelaksana di lapangan. Hal ini yang kemudian diantisipasi oleh BIM agar segala macam bentuk informasi terkait bangunan akan turut tersimpan dalam bentuk digital bersamaan dengan model bangunan dan gambar kerja bangunan tersebut [3]. Berdasarkan paparan di atas, maksud dari penelitian ini adalah selain untuk untuk membuka wawasan mengenai Building Information Modelling sebagai salah satu bentuk perkembangan teknologi dalam bidang konstruksi juga untuk mengetahui perbandingkan alur kerja BIM dengan alur kerja CAD konvensional dengan mengkhususkan pada tahap pekerjaan renovasi sebuah bangunan rumah tinggal.

\section{METODOLOGI}

\subsection{Metode dan Tahapan Penelitian}

Proses renovasi telah dilalui dengan metode "konvensional" dimana bangunan eksisting didokumentasikan terlebih dahulu sebelum dilakukan renovasi oleh kelompok peneliti pertama. Kelompok peneliti kedua akan mencoba "mengulang" proses renovasi tersebut berdasarkan konsep BIM. Pada tahap ini penelitian akan menggunakan metode riset deskriptif saat mengamati masingmasing alur kerja pekerjaan renovasi baik dengan cara konvensional maupun menggunakan konsep BIM.

Tahap selanjutnya, berdasarkan pengamatan masing-masing peneliti untuk menajamkan analisisnya dilakukan metode komparatif dengan membandingkan setiap tahapan yang dilalui kedua proses tersebut sehingga dapat diperoleh keunggulan maupun kekurangan dari konsep BIM dalam penerapannya pada renovasi bangunan rumah tinggal. 
Secara garis besar, tahapan penelitian ini adalah sebagai berikut:

- Studi literatur atau tinjauan pustaka terkait

- Pengumpulan data pengukuran terhadap obyek studi yang akan dikerjakan

- Pembuatan penggambaran dengan masing-masing alur kerja

- Analisis dan perbandingan setiap tahapan pada masing-masing alur kerja

- Kesimpulan

\subsection{Tinjauan Pustaka}

Computer Aided Design (CAD), merupakan satu bentuk otomatisasi yang membantu perancang untuk memperbaiki gambar, spesifikasi, dan elemen-elemen yang berhubungan dengan perancangan yang menggunakan efek grafik khusus dan perhitungan program-program komputer [4]. Lebih lanjut lagi dapat dijabarkan bahwa Computer Aided Design adalah suatu program komputer untuk menggambar suatu produk atau bagian dari suatu produk. Produk yang ingin digambarkan bisa diwakili oleh garisgaris maupun simbol-simbol yang memiliki makna tertentu [5]. Di bidang arsitektur, CAD yang memiliki kemampuan untuk menggambar 2 dimensi dan gambar 3 dimensi tentu sangat membantu dalam penyampaian informasi atau gagasan-gagasan arsitek kepada pemberi tugas. Tidak mengherankan apabila kemudian CAD sangat diminati untuk dipelajari dan diterapkan bagi pihak yang bersinggungan dengan dunia konstruksi dan dengan cepat menggantikan peran meja gambar sebagai alat penggambaran. CAD kemudian berkembang dan dapat terintegrasi dengan perangkat lunak lain seperti CAE (Computer Aided Engineering) dan Computer Aided Manufacturing (CAM).

BIM adalah teknologi revolusioner dan proses yang dengan cepat telah merubah sudut pandang bagaimana memahami perancangan bangunan, pelaksanaan hingga dan pengopersian [6]. Lebih lanjut lagi disebutkan BIM juga memiliki kemampuan membuat konsep desain interaktif yang mewakili gambar fisik dan nyata dari suatu bangunan yang memungkinkan desainer untuk mengidentifikasi kebutuhan klien dan secara efektif memberikan solusi untuk kebutuhan klien [7]. Disisi lain sebetulnya BIM memberikan potensi untuk memodelkan informasi virtual dalam sebuah model tunggal yang menawarkan visualisasi, deteksi benturan, fase konstruksi, dan bahan-bahan serta pengujian model untuk diserahkan dari tim desain (arsitek, surveyor, insinyur konsultasi, dan lain-lain) kepada kontraktor dan sub-kontraktor dan kemudian ke pemiliknya.

Keuntungan dari layanan BIM adalah sebagai berikut [8]:

1. Meminimalisir desain lifecycle dengan meningkatkan kolaborasi antara owner, konsultan dan kontraktor

2. Kualitas tinggi dan akurasi dokumentasi dari proses konstruksi

3. Teknologi BIM digunakan untuk siklus hidup seluruh bangunan, termasuk fasilitas operasi dan pemeliharaan

4. Produk dengan kualitas tinggi dan memperkecil kemungkinan konflik

5. Pemotongan biaya proyek dan meminimalisir limbah bahan konstruksi

6. Meningkatkan manajemen konstruksi

Kata renovasi menurut KBBI memiliki pengertian pembaharuan; peremajaan; penyempurnaan (tentang gedung bangunan dan sebagainya). Renovasi yang merupakan bagian dari kegiatan konservasi, memiliki pengertian modernisasi bangunan bersejarah [9]. Sayangnya, seringkali kegiatan renovasi ini justru menghilangkan wujud dan detail yang penting pada suatu bangunan yang akan dikonservasikan.

Penerapan BIM seperti yang telah diungkapkan sebelumnya, memiliki tujuan untuk melanjutkan informasi yang telah dihimpun sejak awal proses perancangan. Sejak tahap skematik dimana model bangunan mulai dimunculkan, informasi yang terkandung didalamnya digunakan tidak hanya untuk tahap gambar kerja dan pelaksanaan namun sebelumnya dapat dipergunakan pada berbagai tahapan analisis bangunan. 
Pasca konstruksi, bangunan akan memasuki tahap pemeliharaan. Ditahap inilah renovasi mulai dilakukan. Daur atau siklus ini akan terus berulang hingga suatu saat memasuki tahap penghancuran sebagai akhir dari suatu bangunan (Lihat Gambar 1).

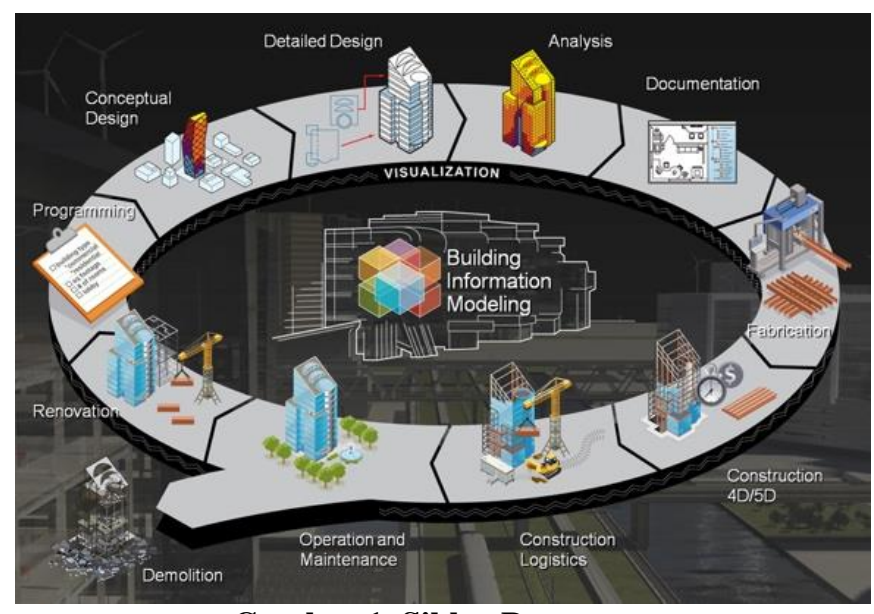

Gambar 1. Siklus Bangunan

Sumber: Building Information Modelling in Design, Construction and Operation, WIT Press [10]

\subsection{Pengumpulan Data}

Langkah awal pengumpulan data adalah berupa data lapangan kondisi sebelum direnovasi seperti yang terlihat pada Gambar 2, baik kondisi luar bangunan maupun bagian dalam bangunan yang disertai dengan data-data pengukuran ulang bangunannya.

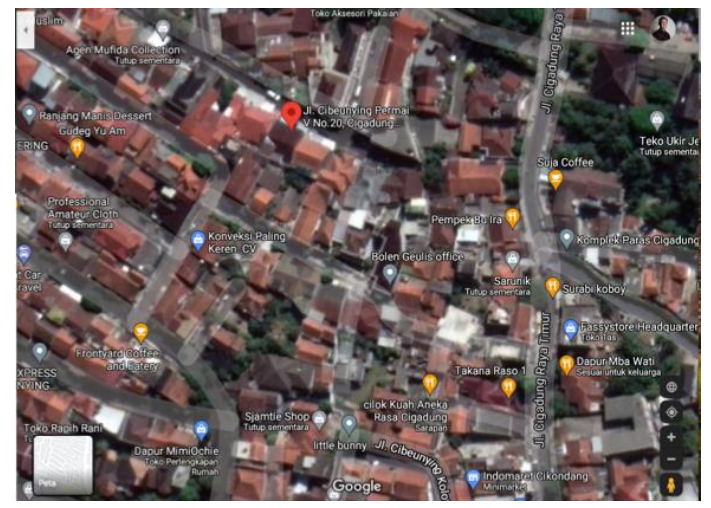

Gambar 2. Lokasi Kasus Studi

Sumber: https://www.google.co.id/maps, 2020

Objek studi adalah rumah tinggal 2 lantai yang berlokasi di Jl. Cibeunying Permai V no.20, Bandung, ditandai dengan titik merah pada Gambar 3.
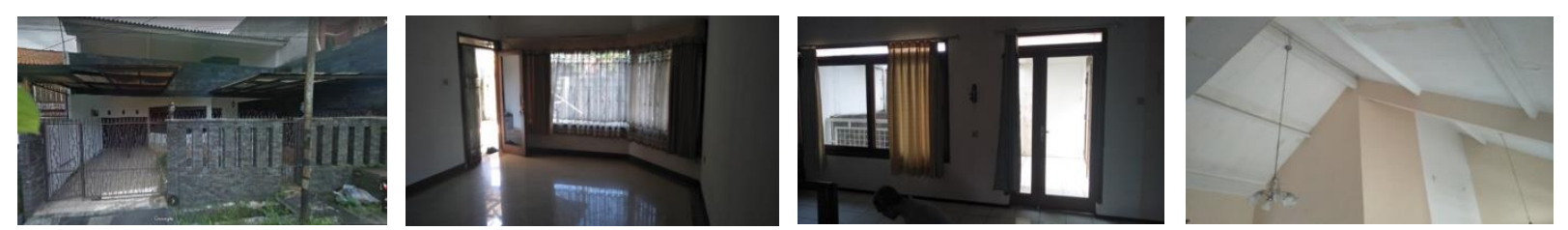

Gambar 3. Kondisi Rumah Sebelum Direnovasi

Sumber: Hasil survey

Langkah berikutnya adalah mengumpulkan gambar-gambar kerja yang dipakai dalam pelaksanaan renovasi rumah tinggal tersebut yang telah diperiksa ulang ukuran-ukurannya untuk kemudian 
digambar ulang oleh peneliti agar mendapatkan perbandingan proses penggambarannya antara alur kerja yang menggunakan CAD maupun yang menggunakan alur kerja BIM (Gambar 4).
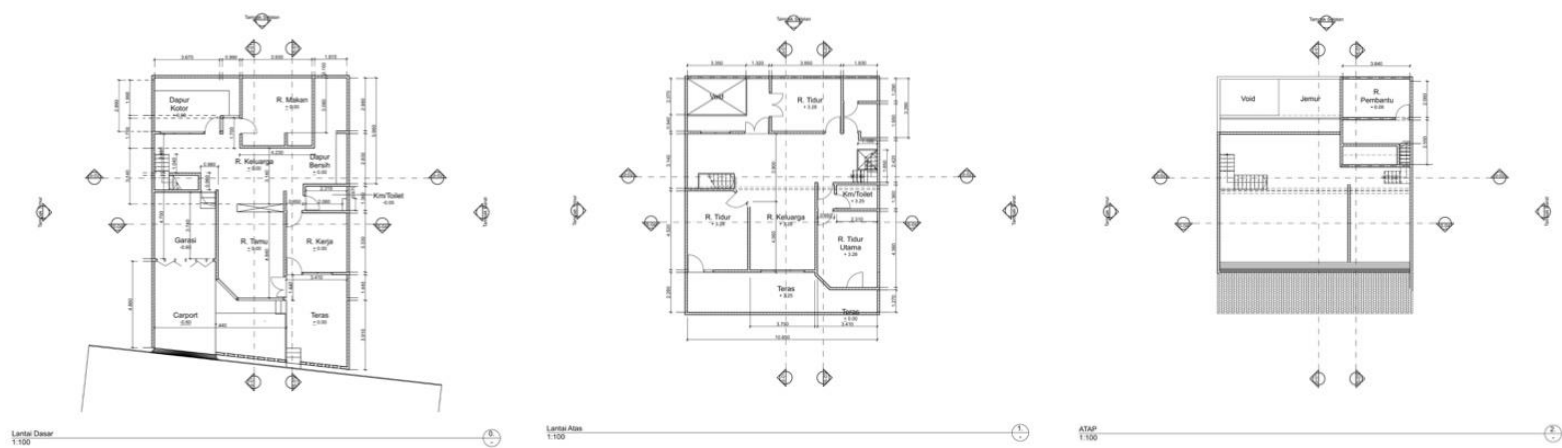

\section{Gambar 4. Gambar Denah Lantai Dasar, Lantai Atas Dan Atap \\ Sumber: Hasil survey}

\subsection{Variabel Penelitian}

Guna mempermudah tercapainya tujuan penelitian, variabel yang digunakan dalam penelitian ini adalah:

- Waktu, dilihat berdasarkan proses pengerjaan masing-masing alur kerja

- Biaya, walaupun tidak didefinitifkan dalam bentuk satuan mata uang

\section{HASIL DAN PEMBAHASAN}

\subsection{Penerapan CAD Dalam Proses Renovasi}

Metode paling umum yang digunakan dalam penggambaran renovasi menggunakan CAD adalah menggambar denah eksistingnya terlebih dahulu, setelah selesai keseluruhannya, denah tersebut digandakan dan ditempatkan di sampingnya untuk kemudian dirubah sesuai gambaran akhir saat bangunannya telah selesai dibangun.

Hal ini mudah dalam pengerjaannya serta pada umumnya pemberi tugas juga tidak mau repot melihat gambar perubahannya dan lebih mudah diterangkan oleh arsitek atau pelaksana bagian mana saja yang akan ditambah atau dihilangkan dengan mengacu pada gambar yang sudah memperlihatkan hasil akhirnya. Bagi pihak yang menghitung volume bangunan, penyajian gambar seperti ini memerlukan pengukuran ulang pada denah eksisting dan memilah bagian mana yang akan menjadi pekerjaan pembongkaran atau pekerjaan pelaksanaan.

Guna mempermudah semua pihak, diperlukan sebuah gambar denah yang memperlihatkan perombakan (ditandai dengan arsir diagonal) dan pemasangan baru (ditandai dengan warna hitam pekat) sebelum menampilkan gambar akhir perubahannya. Secara prinsip maksud dari uraian tersebut dapat dilihat pada Gambar 5.

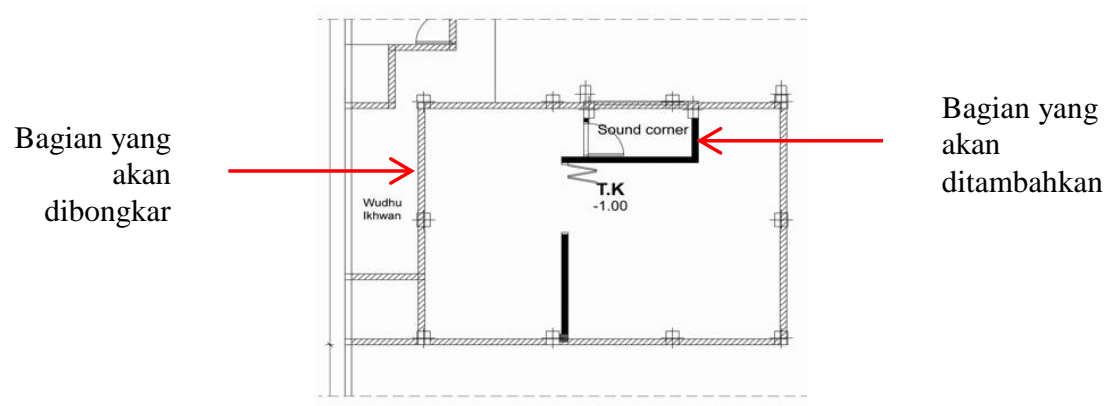

Gambar 5. Metode Penggambaran Yang Akan Direnovasi

Sumber: Hasil analisis 
Sebagai ilustrasi, proses penggambaran perubahan denah yang mengalami pemotongan untuk dihilangkan pada CAD dapat dilihat secara detail, langkah demi langkah pada Gambar 6. Apabila secara kebetulan hanya menghilangkan satu buah dinding, cukup dengan menggunakan perintah hapus (erase) setelah itu dipilih bagian yang akan dihilangkan. Penggambaran penambahan dapat menggunakan perintah garis (line) atau menduplikasi dinding yang sudah ada lalu disesuaikan dengan cara yang sama seperti di atas. Langkah terakhir adalah memberikan arsir diagonal atau hitam pekat sesuai kebutuhannya.

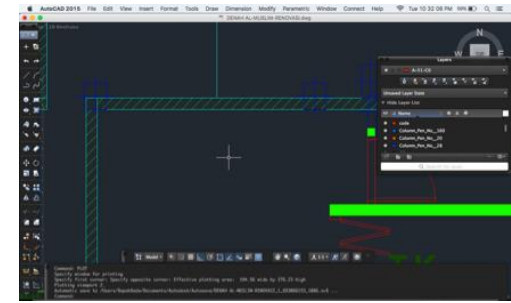

1. Ketik perintah line lalu enter

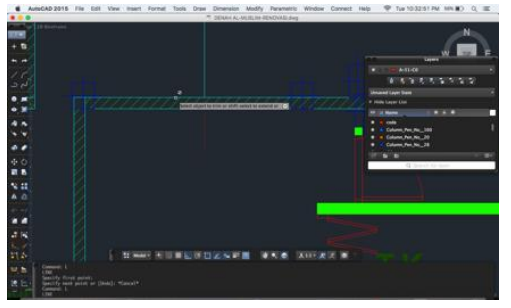

4. Klik pada objek yang akan dihilangkan

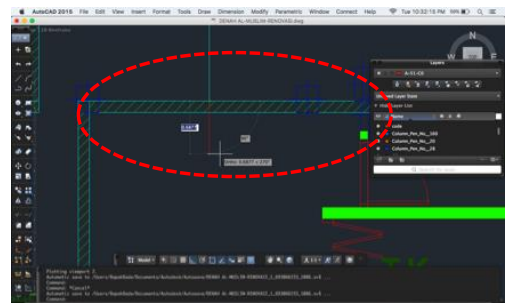

2. Buat garis lurus pada batas dinding yang akan dipotong

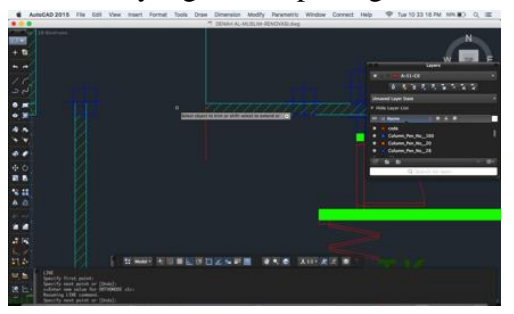

5. Dinding telah terpotong

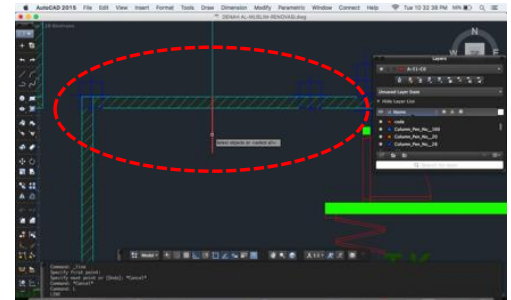

3. Ketik perintah trim lalu enter

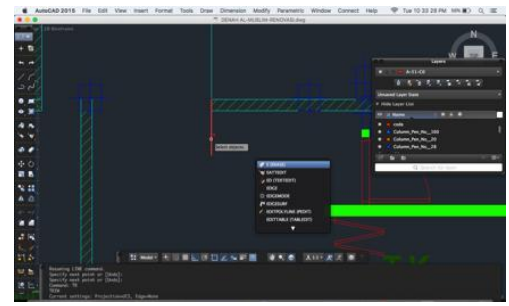

6. Hapus garis bantu yang dibuat diawal

Gambar 6. Proses Perubahan Objek yang Akan Direnovasi pada CAD

Sumber: Hasil analisis

\subsection{Penerapan BIM Dalam Proses Renovasi}

Menggunakan ArchiCad sebagai salah satu software berbasiskan BIM, pada setiap komponen gambar seperti dinding, kolom, balok, slab, dan lainnya cukup ubah status renovasi pada klasifikasi dan properti didalam pengaturan default komponen. Berikut penjelasan secara detail cara mengubah objek yang akan direnovasi pada salah satu denah (Gambar 7).

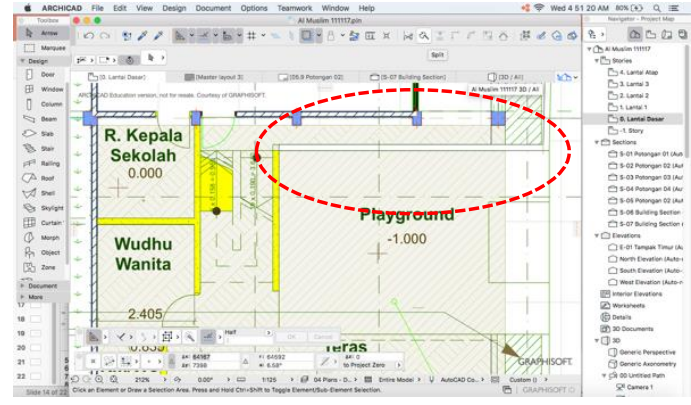

1. Ambil objek dinding yang akan diubah (ditandai dengan oval merah)

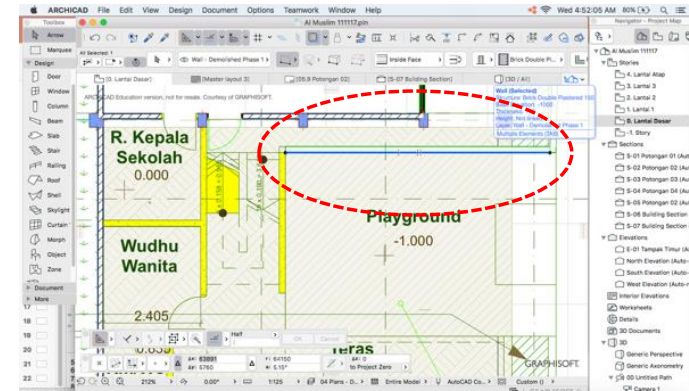

2. Pilih objek menggunakan penunjuk panah 


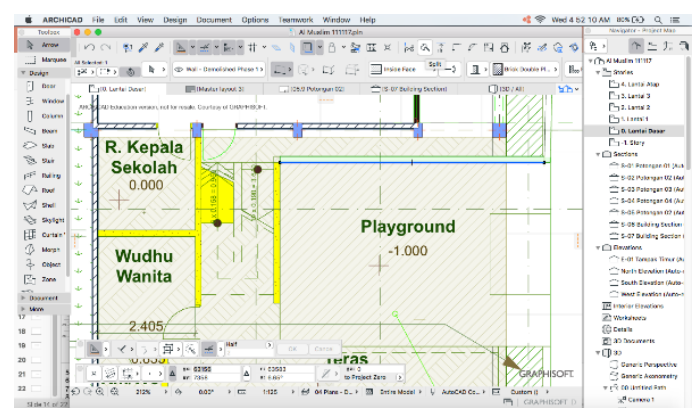

3. Klik axe tool untuk memotong dinding

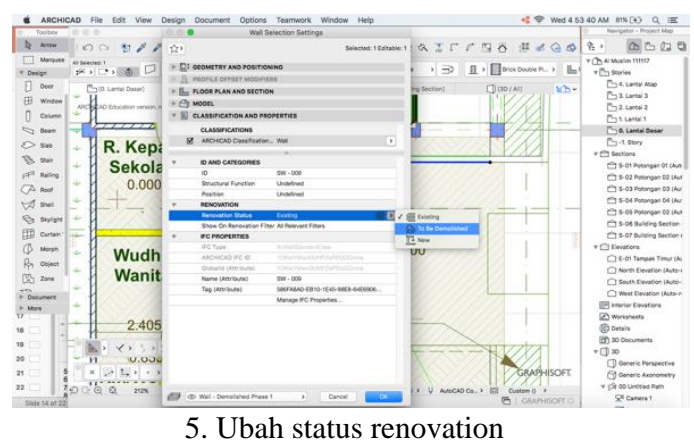

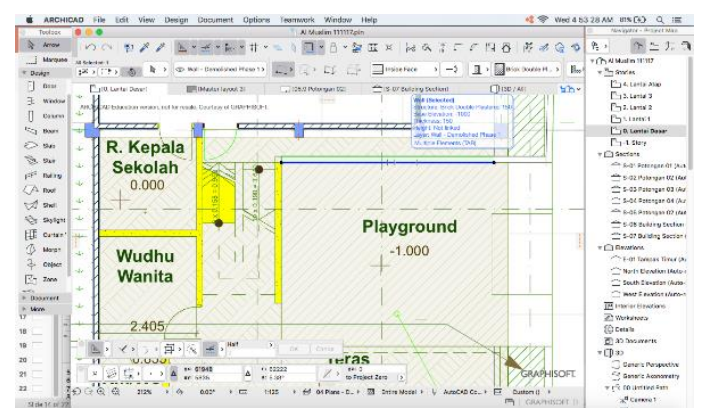

4. Dinding menjadi lebih pendek dari sebelumnya

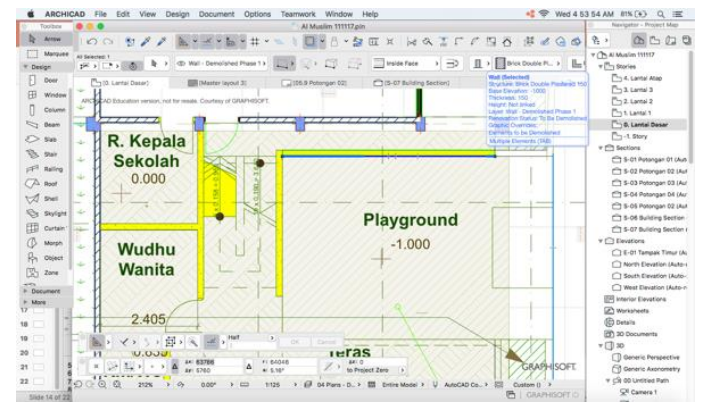

6. Dinding telah berubah status menjadi tembok pembongkaran dengan ditandai warna kuning.

Gambar 7. Proses Perubahan Objek yang Akan Direnovasi

Sumber: Hasil analisis

Denah-denah yang akan dirubah dipilih status renovation yang tersedia menjadi To Be Demolish (ditandai warna kuning) sedangkan bagian bangunan yang baru pemilihan statusnya adalah New Construction (ditandai warna merah) sehingga dalam sekali menggambar dan hanya melakukan perubahan status komponennya akan didapat 4 buah denah sekaligus, denah eksisting, denah renovasi, denah konstruksi baru dan denah akhir setelah renovasi (Gambar 8).
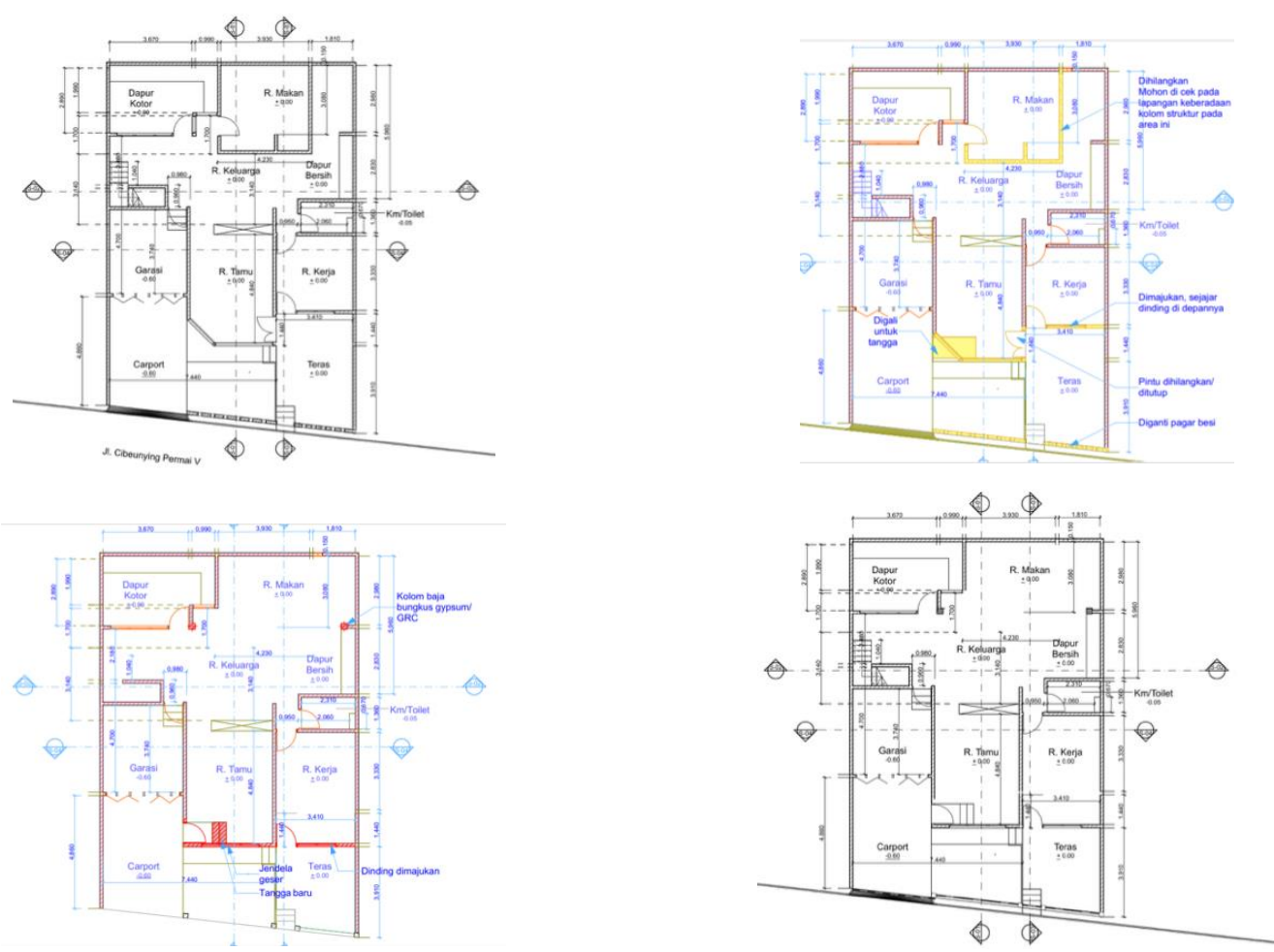

Gambar 8. Tampilan Denah Pada Proses Renovasi Menggunakan BIM

Sumber: Hasil analisis 


\subsection{Komparasi Penggunaan CAD dan BIM Dari Segi Waktu}

Efisiensi waktu sangat terkait dengan proses penggambaran. Berdasarkan proses yang dikerjakan oleh kelompok peneliti pertama dan kedua, berikut komparasi durasi pengerjaan dari kedua metode tersebut dalam proses penggambaran yang dapat dilihat dalam Tabel 1.

Tabel 1. Komparasi Durasi Penggambaran

\begin{tabular}{|c|c|c|c|}
\hline Nama Kegiatan & & Durasi & Timeline \\
\hline \multirow{2}{*}{ Setting awal } & CAD & 1 hari & \\
\hline & BIM & 1 hari & \\
\hline \multirow{2}{*}{ Membuat gambar kerja } & CAD & 8 hari & \\
\hline & BIM & 6 hari & \\
\hline \multirow{2}{*}{ Membuat rencana perubahan } & CAD & 2 hari & \\
\hline & BIM & 1 hari & \\
\hline \multirow{2}{*}{$\begin{array}{l}\text { Membuat perubahan gambar } \\
\text { kerja }\end{array}$} & CAD & 4 hari & \\
\hline & BIM & 2 hari & \\
\hline \multirow{2}{*}{ Membuat gambar 3D } & CAD & 3 hari & \\
\hline & BIM & 1 hari & \\
\hline
\end{tabular}

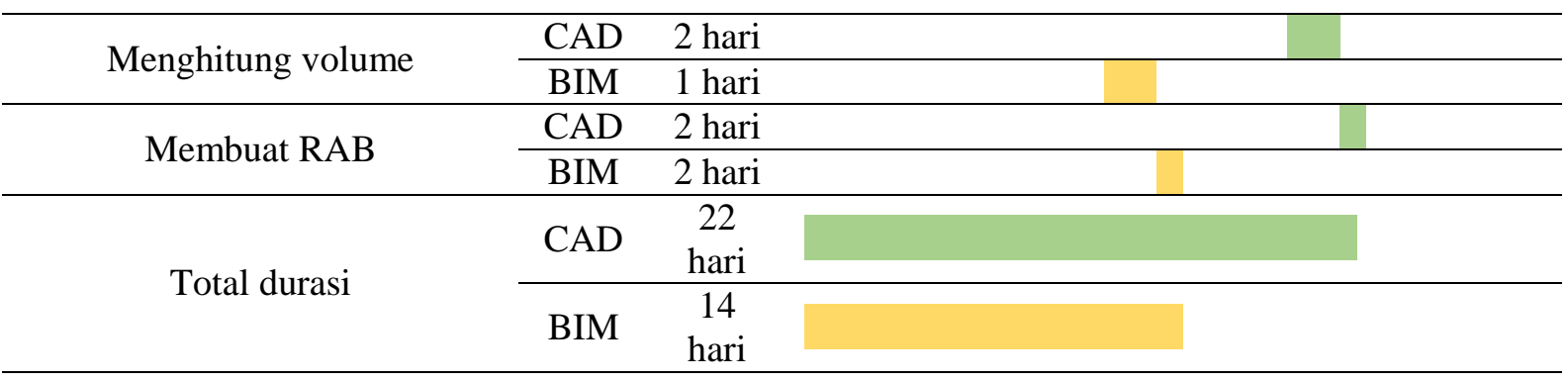

Selisih perbedaan waktu $=8$ hari

Perhitungan persentase efektivitas:

$\frac{100 \% \times 8 \text { hari }}{22 \text { hari }}=36.3 \%$

Keterangan:

\section{Menggunakan CAD \\ Menggunakan BIM}

Hasil perbandingan waktu pengerjaan menunjukan bahwa BIM lebih cepat 8 hari dibandingkan CAD pada perencanaan renovasi bangunan rumah tinggal. Jika dilihat dalam persentase, BIM $36.3 \%$ lebih efektif dalam durasi pengerjaan renovasi rumah tinggal. Guna melihat lebih rinci, proses pengerjaannya dapat dilihat pada Tabel 2 berikut:

Tabel 2. Komparasi Proses Penggambaran

\begin{tabular}{cccc}
\hline Proses & CAD & BIM & \multicolumn{1}{c}{ Keterangan } \\
\hline Pengaturan layer & $\checkmark$ & $\checkmark$ & - \\
\hline Pengaturan unit & $\checkmark$ & $\checkmark$ & \multicolumn{1}{c}{} \\
\hline Pengaturan garis & $\checkmark$ & $\times$ & $\begin{array}{l}\text { CAD menggunakan elemen garis untuk } \\
\text { penggambaran dan dapat diatur terlebih } \\
\text { dahulu agar memiliki lapisan dan arsiran } \\
\text { pada setiap garis yang dibuat }\end{array}$ \\
\hline Pengaturan komposit & $x$ & $\checkmark$ & $\begin{array}{l}\text { BIM memiliki pilihan lapisan dalam setiap } \\
\text { komponen yang digambar dengan istilah }\end{array}$ \\
\hline
\end{tabular}




\begin{tabular}{|c|c|c|c|}
\hline Proses & CAD & BIM & Keterangan \\
\hline & & & komposit \\
\hline Pengaturan lantai & $x$ & $\checkmark$ & $\begin{array}{l}\text { CAD pada umumnya } \\
\text { menghasilkan gambar 2D } \\
\text { diperlukan pengaturan ketinggian lantai }\end{array}$ \\
\hline $\begin{array}{l}\text { Penggambaran denah } \\
\text { dengan garis sebagai } \\
\text { pembentuk }\end{array}$ & $\checkmark$ & $x$ & \\
\hline $\begin{array}{l}\text { Penggambaran model } \\
\text { dengan komponen } \\
\text { sebagai pembentuk }\end{array}$ & $x$ & $\checkmark$ & $\begin{array}{llrr}\text { Penggambaran } & \text { pada } & \text { BIM } & \text { telah } \\
\text { diklasifikasikan } & \text { berdasarkan } & \text { komponen } \\
\text { bangunan } & & \end{array}$ \\
\hline Penyuntingan gambar & $\checkmark$ & $\checkmark$ & \\
\hline $\begin{array}{l}\text { Penggambaran } \\
\text { potongan dan tampak } \\
\text { secara otomatis }\end{array}$ & $x$ & $\checkmark$ & $\begin{array}{l}\text { Gambar potongan dan tampak harus } \\
\text { dikerjakan terpisah pada CAD, sedangkan } \\
\text { pada BIM cukup dengan menempatkan garis } \\
\text { potongan dan tampak maka gambarnya } \\
\text { sudah muncul tinggal melengkapi notasi dan } \\
\text { dimensi }\end{array}$ \\
\hline $\begin{array}{c}\text { Arsir bayangan pada } \\
\text { tampak }\end{array}$ & $x$ & $\checkmark$ & \\
\hline Produk gambar detail & $\checkmark$ & $\checkmark$ & $\begin{array}{l}\text { Pada CAD dilakukan di layout, sedangkan } \\
\text { pada BIM menggunakan pilihan perangkat } \\
\text { detail. Gambar yang muncul keduanya } \\
\text { berdasarkan batasan tampilan yang akan } \\
\text { diiinginkan }\end{array}$ \\
\hline Produk 3D & $x$ & $\checkmark$ & $\begin{array}{l}\text { Secara prinsip penggambaran pada BIM } \\
\text { sebenarnya membuat model 3D sehingga } \\
\text { produk-produk 3D sudah dapat dimunculkan }\end{array}$ \\
\hline Proses & CAD & BIM & Keterangan \\
\hline $\begin{array}{l}\text { Penggambaran denah } \\
\text { pada tahap renovasi }\end{array}$ & $\checkmark$ & $\checkmark$ & $\begin{array}{l}\text { Pembuatan denah menggunakan CAD pada } \\
\text { tahap renovasi diperoleh dengan proses } \\
\text { duplikasi dan editing sedangkan pada BIM } \\
\text { dilakukan editing dan perubahan status } \\
\text { renovasi }\end{array}$ \\
\hline Koordinasi gambar & $x$ & $\checkmark$ & $\begin{array}{l}\text { Pada CAD dilakukan secara manual } \\
\text { sedangkan pada BIM setiap perubahan akan } \\
\text { berdampak langsung pada semua produk } \\
\text { yang ada }\end{array}$ \\
\hline
\end{tabular}

Sumber: Hasil analisis

Berdasarkan tabel di atas terlihat beberapa keunggulan dari BIM jika dibandingkan dengan CAD dari segi waktu dikarenakan terdapat beberapa fasilitas atau perintah yang lebih efisien. BIM juga dapat mengeluarkan secara langsung daftar tipe kusen pintu dan jendela yang dipakai pada suatu bangunan , Gambar 9. Tipe kusen seperti ini pada CAD harus digambarkan secara manual walaupun sumber gambarnya dapat diambil dari denah, tampak atau potongan. 


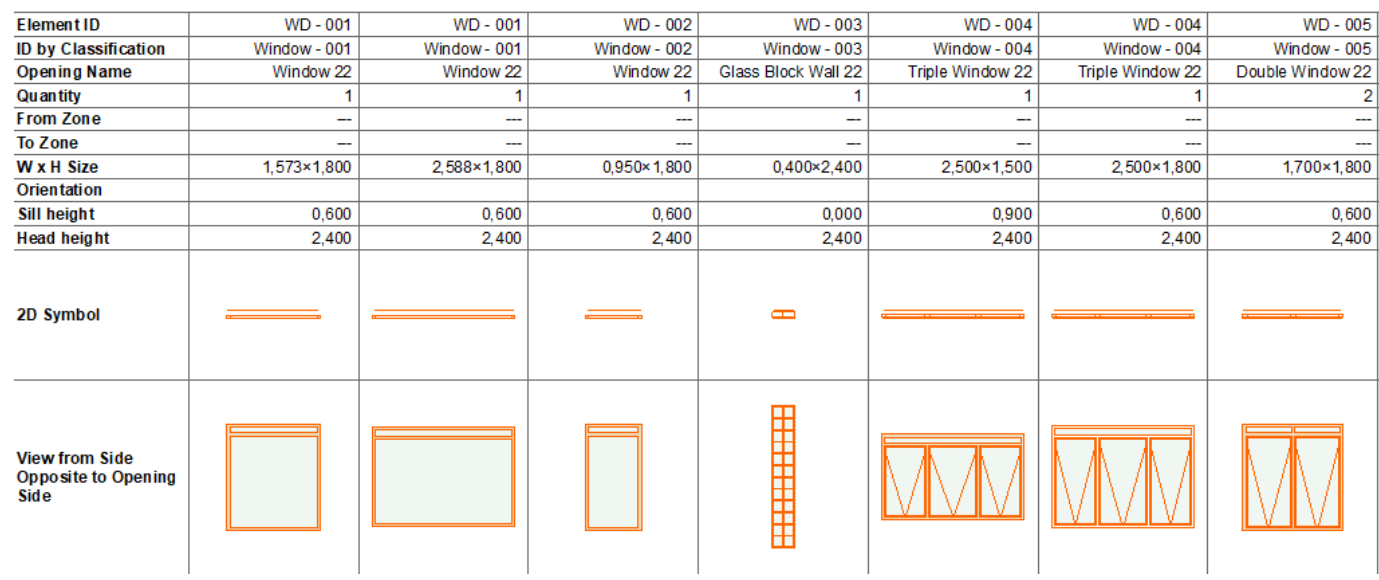

Gambar 9. Daftar Tipe Kusen Jendela Pada BIM

Sumber: Hasil analisis

\subsection{Komparasi Penggunaan CAD dan BIM Dari Segi Biaya}

Sejauh ini, melihat adanya penghematan waktu dalam pengerjaan penggambaran dengan menggunakan BIM mengindikasikan jumlah tenaga kerja juga dapat dihemat. Contoh yang paling mudah tentunya dalam pengerjaan gambar-gambar 3D. Proses yang lebih efisien dalam produktifitas gambar menjadikan seseorang memiliki waktu yang cukup untuk menggambar tampilan 3D suatu bangunan. Berbeda dengan penggunaan $\mathrm{CAD}$ yang membutuhkan software eksternal yang kemungkinan dioperasikan oleh orang lain.

\section{SIMPULAN}

Berdasarkan tabel kesimpulan (Tabel 3) serta penelitian yang dilakukan dengan proses pengulangan renovasi menggunakan BIM mengenai perbandingan waktu dan biaya maka beberapa kesimpulan yang dapat diambil adalah sebagai berikut:

- $\quad$ Menggunakan aplikasi BIM dapat menghemat waktu perencanaan sebesar 36.3\%.

- Penggunaan BIM dapat meminimalisir sumber daya manusia yang lebih efisien.

- Penghematan waktu pengerjaan dan sumber daya manusia menjadikan biaya yang harus dikeluarkan dalam penggambaran menjadi lebih sedikit.

- BIM memiliki kekurangan juga yaitu harga lisensi yang mahal serta membutuhkan spesifikasi hardware yang tinggi.

- Mempelajari BIM memerlukan keseriusan dan waktu yang cukup panjang untuk menguasai keseluruhan cara kerja software tersebut.

Tabel 3. Kesimpulan Komparasi BIM dan CAD

\begin{tabular}{clcc}
\hline No. & \multicolumn{1}{c}{ Kriteria Keunggulan } & BIM & CAD \\
\hline 1 & Durasi Pengerjaan Gambar & $\bullet$ & \\
\hline 2 & Biaya Pengerjaan & $\bullet$ & \\
\hline 3 & Kebenaran Gambar & $\bullet$ & $\bullet$ \\
\hline 4 & Kelengkapan Data Gambar & $\bullet$ & $\bullet$ \\
\hline 5 & Harga Software & & \\
\hline 6 & Kemudahan Software & & 3 \\
\hline 7 & Detail Gambar & $\bullet$ & 5 \\
\hline 8 & Data Struktur dan Konstruksi & Total Poin &
\end{tabular}

Sumber: Hasil analisis 


\section{DAFTAR PUSTAKA}

[1] Berlian, Cinthia Ayu, dkk, Perbandingan Efisiensi Waktu, Biaya Dan Sumber Daya Manusia Antara Metode Building Information Modelling (BIM) Dan Konvensional (Studi Kasus: Perencanaan Gedung 20 Lantai). Jurnal Karya Teknik Sipil Universitas Diponegoro, Volume 5, Nomor 2, Tahun 2016, Halaman 220 - 229.

[2] Hanifah, Yulita, Awarness dan Pemanfaatan BIM: Studi Eksplorasi. Temu Ilmiah IPLBI 2016.

[3] D. Helander, V. Singh, BIM in Building Renovation Projects : What is the useful minimum information requirement? International Journal, Product Lifecycle Management. Vol. 9, No. 1, 2016, p 65-86. ISSN 1743-5110.

[4] "Penjelasan CAD dan Kegunaan Dalam Manufaktur| William Alexander." [Online]. Available: http://williamalexande.blogspot.com/2017/06/penjelasan-cad-dan-kegunaan-dalam.html. [Accessed: 16-Jan-2021]

[5] Y. Setyoadi, K. Latifah, Integrasi Software CAD-CAM Dalam Sistem Operasi Mesin Bubut CNC. Jurnal Informatika Upgris (JIU) Volume 1, Nomor 2, Tahun 2015.

[6] R. Minawati, dkk, Manfaat Penggunaan Software Tekla Building Information Modeling (BIM) Pada Proyek Design-Build. Jurnal Dimensi Utama Teknik Sipil Universitas Petra Surabaya, Volume 4, Nomor 2, Tahun 2017.

[7] A.C. Dace, Building Information Modelling: The Web $3 d$ Application for AEC. Perugia, ACM, Italy. 2007.

[8] Rayendra, Soemardi, Biemo W. Studi Aplikasi Teknologi Building Information Modelling Untuk Pra-Konstruksi. Simposium Nasional RAPI XIII - 2014 FT UMS, ISSN 1412-9612. 2014

[9] DH, Harastoeti. 100 Bangunan Cagar Budaya Di Bandung, CSS Publish, Bandung, 2011. ISBN: 978-979-17433-8-9.

[10] Building Information Modelling in Design Construction and Operation, Editor: Mahdjoubi, L., Brebbia, C.A., Laing, R., WIT Press, Southampton, Boston, 2015. 